\title{
Remodelling the role of facilitating conditions for Google Classroom acceptance: A revision of UTAUT2
}

\author{
Brandford Bervell \\ College of Distance Education, University of Cape Coast, Ghana; Centre for Instructional Technology \& \\ Multimedia, Universiti Sains Malaysia, Malaysia
}

Jeya Amantha Kumar

Centre for Instructional Technology \& Multimedia, Universiti Sains Malaysia, Malaysia

Valentina Arkorful

College of Distance Education, University of Cape Coast, Ghana

Emmanuel Manu Agyapong

Sam Jonah Library, University of Cape Coast, Ghana

\section{Sharifah Osman}

School of Education, Universiti Teknologi Malaysia, Malaysia

\begin{abstract}
Online learning environments have become a contemporary component of global tertiary education due to their affordances. These environments are hinged on internet-based learning management systems and one such tool is Google Classroom. However, empirical studies have indicated that gaps exist in determining how Google Classroom influences students' behavioural intention to use it for online learning. Accordingly, this study defines a model based on the unified theory of acceptance and technology 2 (UTAUT2) to examine the relationship between facilitating conditions and other variables towards intention formation for Google Classroom usage. Based on a mixed method using the explanatory sequential design, survey data from 163 students were initially analysed using partial least squares structural equation modelling followed by a qualitative approach based on open-ended questions for thematic analysis. Results from the partial least squares structural equation modelling approach validated the hypothesised model confirming the significant predictive relationship of facilitating conditions with effort expectancy, hedonic motivation, habit and social influence but had an insignificant relationship with behavioural intention. Furthermore, hedonic motivation and habit were the main predictors of behavioural intention by masking the role of facilitating conditions. Subsequently, the qualitative outcome indicated that habit and perceived control of using Google applications influence hedonic motivation. Finally, recommendations were made to universities towards policy formation and practice of virtual learning using Google Classroom.
\end{abstract}

Implications for practice or policy:

- Higher education institutions should create an environment for students to be motivated and enjoy Google Classroom use.

- Universities should provide Internet, technical and pedagogical support for students' Google Classroom use.

- Universities should explain to students the affordances of using Google Classroom.

- Universities should encourage students to acquire access gadgets (smartphones or tablets) for Google Classroom use.

Keywords: Google Classroom, higher education, facilitating conditions, technology acceptance, UTAUT2

\section{Introduction}

Technology integration in education is pervasive and trending and has been rapidly adopted for various educational environments. To date, the integration of computers and smartphones has been fundamental in facilitating virtual classrooms as a platform to dispense knowledge in and out of the classroom (de Campos 
Filho et al., 2019). Furthermore, platforms such as virtual learning environments can enable pedagogical activities through learning management (Awang et al., 2018), remote accessibility, collaboration and communication (Iftakhar, 2016). Accordingly, this value and potential catalysts have stimulated higher education institutions to use virtual learning environments such as Moodle, Blackboard (Hamutoglu et al., 2019) and Google Classroom (GC) (de Campos Filho et al., 2019; Iftakhar, 2016) widely as a means to promote online learning requirements. The exponential adoption of these platforms has been further influenced by a need to convert traditional classes to fully online classes due to the COVID-19 pandemic; and one of the leading virtual learning environments gaining much popularity is GC (Ansong-Gyimah, 2020).

GC has been defined as a learning management system (Jordan \& Duckett, 2018; Kumar \& Bervell, 2019) and a virtual learning environment (Awang et al., 2019; Beaumont, 2018; Saeed Al-Maroof \& Al-Emran, 2018). It has become a popular choice in higher education institutions (Jakkaew \& Hemrungrote, 2017) since it first emerged in 2014 (Saeed Al-Maroof \& Al-Emran, 2018) as a free online learning platform that promotes strategies for dynamic learning (de Campos Filho et al., 2019), blended learning (Barari et al., 2020; Raman \& Rathakrishnan, 2020), collaborative learning (Beaumont, 2018) and mobile learning (Kumar et al., 2020). GC empowers classroom instruction as a practical learner-centred tool (Raman \& Rathakrishnan, 2020) and facilitates online and distance learning (Saeed Al-Maroof \& Al-Emran, 2018). Through GC, students have an easy and reliable platform to access learning content, communicate with their instructors, manage learning activities and submit their assignments (Kumar et al., 2020). Empirical studies have also indicated the benefits of GC as an environment that promotes student-oriented learning, inquiry learning, dialogue, active learning and creative thinking (Shaharanee et al., 2016). Moreover, GC's paperless concept (Sudarsana et al., 2019) has been a cost-effective alternative for students to execute learning activities (Saeed Al-Maroof \& Al-Emran, 2018), which has made it a popular choice, even with students.

Additionally, GC is also positioned as a fundamental and straightforward virtual learning environment that affords teaching and learning diversification. The automatic integration of Google education applications, for instance, Google Drive, Calendar, Docs, Sheets, Slides, Google Meet and Gmail (Madhavi \& Mohan, 2018), has been well received among students in higher education institutions (Rejón-Guardia et al., 2019). Furthermore, GC supports numerous collaborations with application program interfaces (APIs) through information disclosure with third-party educational software tools such as Flipgrid, Buncee and Edpuzzle (Heggart et al., 2018). Nonetheless, GC is not without limitations. Empirical findings have indicated that due to its simple and inclusive design, the platform has been reported to be unengaging (Alia \& Hamtini, 2019) and lacking in personalisation and interaction with peers (Kumar et al., 2020). Due to these challenges, Eraslan Yalcin and Kutlu (2019) stipulated that identifying factors that influence students' intention and acceptance of using a learning system is essential. Although studies related to GC acceptance and behavioural intention are limited (Kumar \& Bervell, 2019; Saeed Al-Maroof \& Al-Emran, 2018), understanding intention is crucial in determining continuous use in higher learning (Bazelais et al., 2018). Furthermore, the need to explore GC adaptation is also mediated and moderated by factors such as demographic characteristics, technical competencies (Abazi-Bexheti et al., 2018), cultures and countries and could differ based on context (Efiloğlu Kurt \& Tingöy, 2017). Hence, this poses a need to explore the acceptance and use of GC in new contexts to identify if the same values, beliefs and approaches are also relevant for different higher education institutions (Efiloğlu Kurt \& Tingöy, 2017; Kumar et al., 2020; Saeed Al-Maroof \& Al-Emran, 2018).

Likewise, to promote and facilitate GC technology, the presence of enabling conditions surrounding its usage is essential. Enabling conditions for technology use in the educational setting account for the availability and accessibility of resources that promote the acceptance and use of learning management systems (Bervell \& Umar, 2017). Given this, we specifically studied the acceptance of GC as a virtual learning environment by investigating the role of facilitating conditions as reflected by the unified theory of acceptance and use of technology 2 (UTAUT2) model. UTAUT2 is used as a baseline model (Venkatesh et al., 2016) to hypothesise relationships while modifying and exploring new relationships based on empirical research on GC acceptance. According to Venkatesh et al. (2008), behavioural intention and facilitating conditions are the main factors behind the use of technology at an individual level. Maruping et al. (2017) defined facilitating conditions as a non-volitional factor representing internal facets depicted through effort expectancy and performance expectancy or external facets depicted through the accessibility of environments based on resources and support for using a technology. These facets are put in place to 
eliminate constraints users encounter when using a system (Venkatesh et al., 2008). Nevertheless, Huang et al. (2020) have argued that limited studies reflect the role of facilitating conditions as an arbitrating factor influencing intention. Liu et al. (2018) have described facilitating conditions as a dominant factor in predicting intention compared to the system's usefulness, while studies from other online services such as that by Chen and Aklikokou (2020) have confirmed its positive relationship with ease of use. Furthermore, Khechine et al. (2020) have explained that facilitating conditions have an essential role in reinforcing adoption of online learning, which Huang et al. (2020) argued is fundamental in predicting ease of use especially, when considering technology affordance in developing countries.

Consequently, the uniqueness of this study conforms to the aforementioned demand by repositioning facilitating conditions to examine their role in influencing behavioural intention directly and as a factor that influences other constructs in UTAUT2 that arbitrate behavioural intention. We hypothesised that due to the online nature of GC, information and communication technology resources and the support the learners perceive are fundamental in exploring factors such as accessibility and motivation towards using and adopting a virtual learning environment. Thus, this study adds to the literature relating to GC acceptance in Malaysian higher education while investigating and identifying new relationships based on the possible role of facilitating conditions towards predicting behavioural intention. Accordingly, we intended to answer these research questions:

- What is the effect of facilitating conditions on performance expectancy, effort expectancy, social influence, habit and hedonic motivation towards the acceptance of GC as a virtual learning environment in higher education?

- What is the effect of facilitating conditions on behavioural intention of GC as a virtual learning environment in higher education?

- What is the validity and reliability of the formulated modified model on the effects of facilitating conditions on the acceptance of GC as a virtual learning environment in higher education?

We adopted a sequential explanatory mixed-methods design in which the qualitative phase was conducted after the quantitative phase. The purpose of conducting the qualitative phase was to explain and understand the quantitative results (Creswell \& Clark, 2011). According to Huang et al. (2020), this is essential to obtain a holistic view and identify how facilitating conditions influence the adoption of an online learning system such as GC.

\section{Literature review}

The growing interest in how technology is used and accepted has spurred the growth of behavioural models. According to Efiloğlu Kurt and Tingöy (2017), various models have been developed in this context starting from the technology acceptance model (TAM), its extended versions and now focusing on UTAUT. TAM was based on the theory of reasoned action (TRA) to rationalise the acceptance and intention to use an information system (Davis, 1989), where factors such as perceived usefulness and perceived ease of use were used to predict the effectiveness of a technology (Bazelais et al., 2018). Using TAM and TRA versions with six other theories - namely innovation diffusion theory, social cognitive theory, motivational model, theory of planned behaviour, combined technology acceptance model and theory of planned behaviour, and model of personal computer utilisation - Venkatesh et al. (2003) developed UTAUT. The combination of these eight theories resulted in a much more complete understanding of factors influencing technology acceptance (Zwain, 2019). TAM and UTAUT remain the two main baseline models in this context and have evolved with several extensions and modifications (Scherer et al., 2019). In the case of UTAUT, the extension and integration are usually done based on three different scenarios: (a) new context such as new technology, new user population and new cultural setting, (b) new endogenous constructs and (c) new exogenous variables which are determined outside the model (Venkatesh et al., 2016). UTAUT has been found to account for about $70 \%$ of the variance $\left(\mathrm{R}^{2}\right)$ of intention and $48 \%$ (adjusted $\mathrm{R}^{2}$ ) of variance of technology use based on four main factors: performance expectancy, effort expectancy, social influence and facilitating conditions, where performance expectancy, effort expectancy and social influence were theorised to influence behavioural intention (Venkatesh et al., 2003). In contrast, behavioural intention and facilitating conditions influenced technology use behaviour (Venkatesh et al., 2016). These constructs were defined by Venkatesh et al. (2003) as: 
- Performance expectancy reflects the degree to which a user believes a system helps them achieve their task.

- Effort expectancy is the effortlessness of using a system.

- Social influence is the extent to which other people (social circle) influence the use behaviour.

- Facilitating conditions is the perceived belief that a person has support from their organisation which includes technical support that are necessary to sustain the use of a system.

Gender, age, experience and voluntariness are also included as moderating factors in UTAUT to control individual differences to predict behavioural intention and use behaviour. Moreover, Venkatesh et al. (2012) extended the model by incorporating three more constructs:

- hedonic motivation as the degree of fun or pleasure from using a system

- price value as the balance between the system's benefits towards the price paid for it

- habit as the degree of preference to perform behaviours in using the system automatically.

We reintroduced Venkatesh et al.'s (2012) new extended model as UTAUT2 (Figure 1). Accordingly, UTAUT2 explained $74 \%$ of the variance of intention in using an IS compared to UTAUT, explaining about $70 \%$ (Venkatesh et al., 2012). The difference with the initial findings was accounted for based on the context of application, where UTAUT was initially developed focusing on organisational use (Venkatesh et al., 2003) and UTAUT2 for technology consumerism. According to Scherer et al. (2019), UTAUT is inadequate in explaining factors predicting use behaviour. Hence, we opted for UTAUT2, where the initial findings in the same context by Kumar and Bervell (2019) showed that the model explained a total variance of $63 \%$ of behavioural intention and $70 \%$ of use behaviour. Nevertheless, the challenges in adopting technology often relate to human factors such as cultural beliefs, security, information and communication technology infrastructures and higher education organisational policies (Ohei \& Brink, 2019).

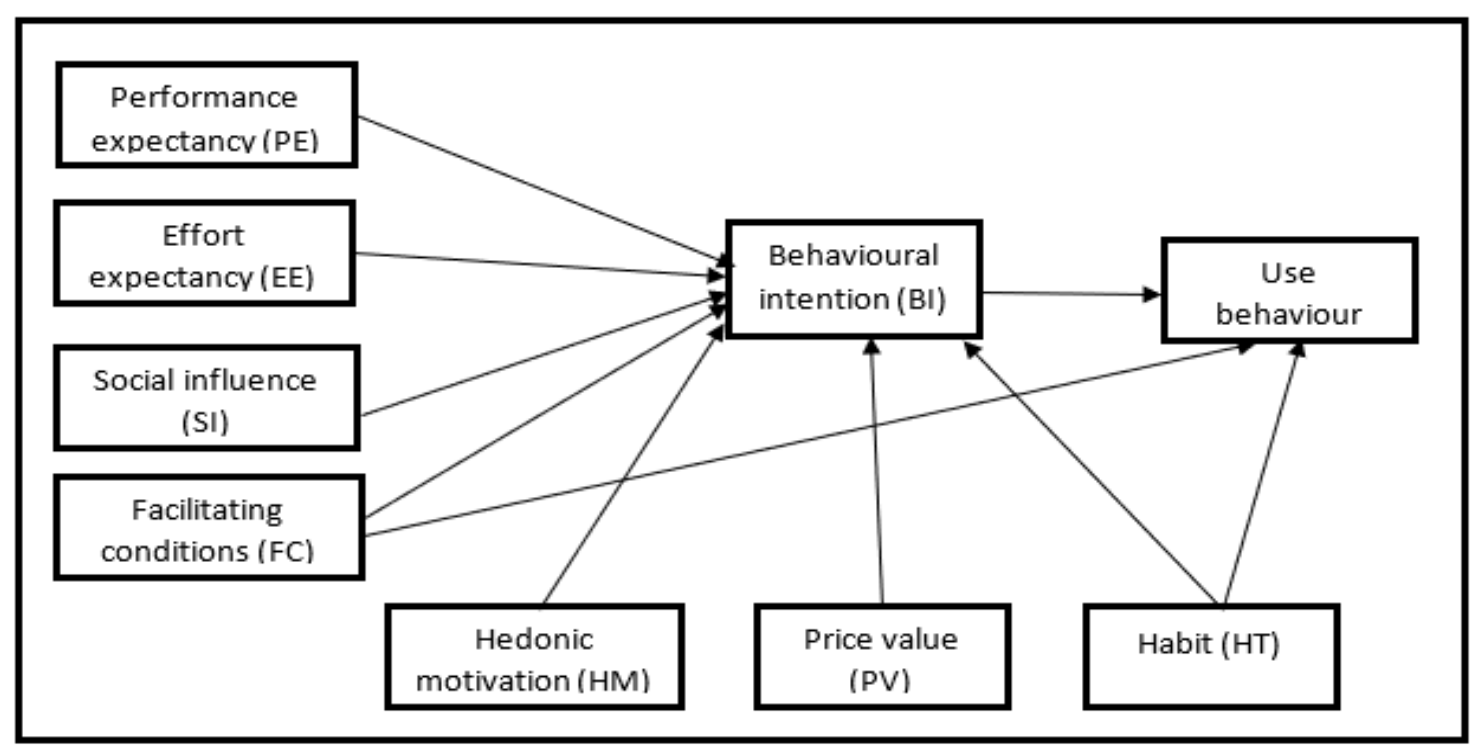

Figure 1. UTAUT2 (Venkatesh et al, 2012, p. 160)

In view of that, we deduced that one of the main factors predicting intention and use is facilitating conditions, which is an antecedent to other factors when learning online. For example, it will be challenging to collaborate and access learning content without Internet access, which influences students' effort expectancy and perceived usefulness. Conversely, these challenges account for lack of motivation in using a platform, which will deter habitualisation. Therefore, we explored how facilitating conditions stands as an exogenous factor (external factor) in determining endogenous factors towards behavioural intention and use behaviour (Figure 2). 


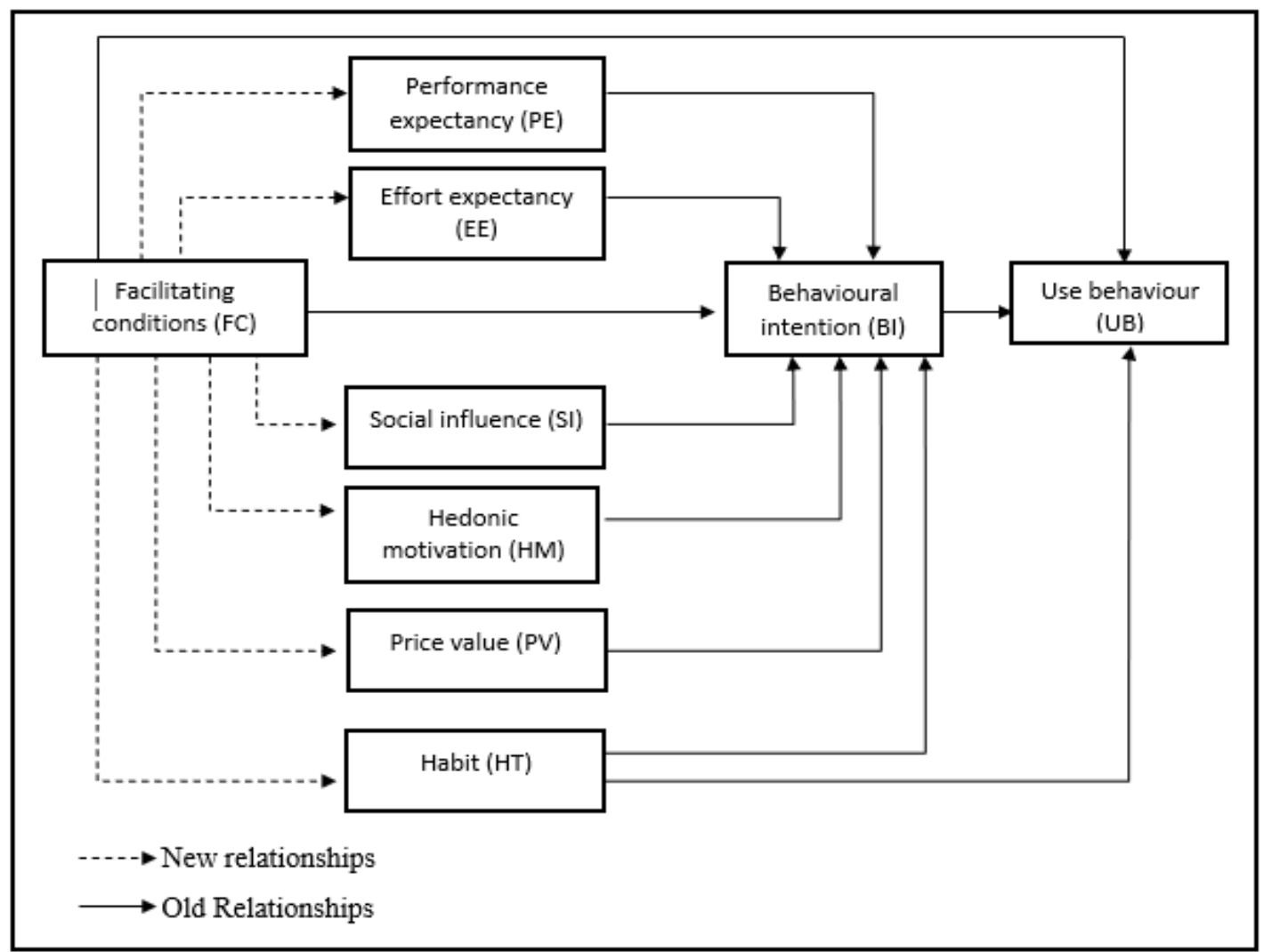

Figure 2. Proposed baseline model of a modified UTAUT2

\section{Hypotheses development}

This study's hypotheses development is discussed based on the main latent variables used to predict use behaviour and behavioural intention.

\section{Facilitating conditions}

Efiloğlu Kurt and Tingöy (2017) defined facilitating conditions as the perceived credence users have of a virtual learning environment as an effective system with the necessary infrastructure to facilitate its use. Khechine et al. (2020) defined facilitating conditions as the learning support that the learners perceive in using a system from other individuals, institutions and technical facilities. It implies that easy access to administrative and organisational support is fundamental for online learning adaptation (Iftakhar, 2016) and the absence of this support will affect behavioural intention and use behaviour. Based on UTAUT2, facilitating conditions as a factor has a direct linear relationship with behavioural intention and use behaviour (Jakkaew \& Hemrungrote, 2017; Venkatesh et al., 2016). However, more recent GC acceptance studies have rejected a direct relationship between these constructs (Kumar \& Bervell, 2019; Moorthy et al., 2019; Raman \& Rathakrishnan, 2020), as facilitating conditions tends to mask the relationship between behavioural intention and use behaviour (Efiloğlu Kurt \& Tingöy, 2017). Furthermore, Maruping et al. (2017) have described the role of facilitating conditions as being represented through effort expectancy to influence behavioural intention directly and not as a direct influence of behavioural intention. Nonetheless, as facilitating conditions could characterise effort expectancy, it is also predicted to influence hedonic motivation and effort expectancy (Lowry et al., 2013). In contrast, a study by Huang et al. (2020) found a non-significant relationship between facilitating conditions and effort expectancy in predicting behavioural intention. Rahmad et al. (2019) have added that integrating alternative resources (e.g., application program interfaces), the Internet and mobile learning facilities are part of GC's definition of the facilitating conditions. According to Zwain (2019), technical support and Internet speed improve learning experiences that encourage use, which will be accepted as part of students' learning routines and habitualised behaviour. Therefore, we hypothesised that facilitating conditions while also supporting hedonic motivation (H1) and effort expectancy (H3), has the potential to influence habit (H3). 
Next, we hypothesised that facilitating conditions has the potential to influence social influence. Social influence is indicated as being an essential construct for mandatory use of an information system (Venkatesh et al., 2003) as implied in this study. Venkatesh et al. (2008) described social influence as a construct rooted in social networking relationships and it may directly or indirectly affect behavioural intention. Furthermore, the mobile nature of GC and API integration were found to be factors influencing GC being recommended as an exemplary virtual learning environment in higher education (Kumar et al., 2020). While promoting ease of use and meaningful learning, students are motivated to recommend GC to their peers (Kumar \& Bervell, 2019) due to their confidence in its effectiveness (Bervell \& Umar, 2017). Therefore, we also hypothesised that:

- H1: There is a positive relationship between facilitating conditions and hedonic motivation towards GC usage intentions.

- H2: There is a positive relationship between facilitating conditions and habit towards GC usage intentions.

- H3: There is a positive relationship between facilitating conditions and effort expectancy towards GC usage intentions.

- H4: There is a positive relationship between facilitating conditions and social influence towards GC usage intentions.

\section{Habit}

Assensoh-Kodua and Ngwane (2015) described habit as a behaviour controller that strengthens the use of a system. According to Venkatesh et al. (2012), habit has both direct and moderating effect on behavioural intention and use behaviour. Habit is defined as routinely performed behaviours that promote an automatic response. In information system studies, habit is also a product of experience and familiarity due to the extent of interaction (Venkatesh et al., 2012). Limayem and Cheung (2011) and Zwain (2019) found habit as influencing the continuous use of a virtual learning environment. According to Tamilmani et al. (2019), habitual behaviour may be observed to measure behavioural intention but not use behaviour if the technology is in its introductory stage or when the use is mandatory. Habit has also been found to influence behavioural intention for GC (Jakkaew \& Hemrungrote, 2017; Kumar \& Bervell, 2019). However, Ain et al. (2016) claimed otherwise in mandatory situations. Ain et al. (2016) added that compulsory educational activities might be the basis of social pressure in a learning community related to social influence.

Similarly, Kumar and Bervell (2019) found that in GC, habit positively influences social influence. Limayem et al. (2007) also claimed that habit is influenced by an IS complexity reflected as effort expectancy. Furthermore, the ease of using a system has a propensity to cause a favourable disposition among students thus, creating a positive social influence towards system use. This relationship has been highlighted in other studies such as from Bervell and Umar (2017) and Mensah (2019). Finally, empirical findings in GC found habit to be a strong determinant of effort expectancy as familiarity influences easiness in system navigation (Kumar \& Bervell, 2019). Concurrently, Tamilmani et al. (2019) have added that social influence moderates the relationship between habit and behavioural intention. Therefore, we hypothesised the following relationships for habit and effort expectancy:

- H5: Habit has a positive relationship with effort expectancy towards GC usage intentions.

- H6: Effort expectancy has a positive relationship with social influence towards GC usage intentions.

- H7: Habit has a positive relationship with social influence towards GC usage intentions.

- H11: Habit has a positive relationship with behavioural intention towards GC usage intentions.

\section{Behavioural intention and use behaviour}

We hypothesised the linear relationships in UTAUT2 as H8, H9, H10, H11 and H12. First, we hypothesised that social influence effects behavioural intention in any mandatory use of a virtual learning environment. Social influence is defined by the subjective influence of instructors and peers and strongly influences the behavioural intention to use a virtual learning environment. In this context, it is reflected as an extrinsic motivation for behavioural intention. Empirical findings for GC (Jakkaew \& Hemrungrote, 2017; Kumar \& Bervell, 2019; Raman \& Rathakrishnan, 2020 ; Saeed Al-Maroof \& Al-Emran, 2018) and in other virtual 
learning environments (Nicholas-Omoregbe et al., 2017) have indicated a strong relationship between these constructs. Additionally, within the same GC studies, effort expectancy influenced behavioural intention, where Ansong-Gyimah (2020) described effort expectancy as a strong predictor of GC's continuous use. Moreover, attributes of GC such as ease to use and flexibility due to its mobile nature (Iftakhar, 2016) are some of the conditions found to influence behavioural intention. Subsequently, hedonic motivation was also found to influence behavioural intention in GC adoption. De Campos Filho et al. (2019) have claimed that GC motivates and satisfies users' learning needs for a virtual learning platform. Zwain (2019) added that hedonic motivation is one of the primary factors that strongly influence the intention to use a virtual learning environment.

Furthermore, facilitating conditions provide a platform for users to form intentions (favourable or unfavourable) towards using a novel technology (Bervell \& Umar, 2017). The availability and accessibility of appropriate and needed resources for technology uptake are essential in defining the intentions of potential users of a system. The assurance of an enabling environment equipped with adequate resources can tune users' intention towards a positive orientation. In terms of other determinants of behavioural intention, Saeed Al-Maroof et al. (2021) defined effort expectancy and hedonic motivation as primary factors determining students' acceptance of a virtual learning environment. Lastly, we hypothesised behavioural intention as the central construct that influences use behaviour (Jakkaew \& Hemrungrote, 2017; Saeed Al-Maroof \& Al-Emran, 2018; Venkatesh et al., 2003). Yet, Efiloğlu Kurt and Tingöy (2017) indicated a vast difference in behavioural intention and use behaviour based on different countries, where behavioural intention may not predict use behaviour especially if resource limitations can be attributed to facilitating conditions. Nevertheless, we hypothesised the following relationships:

- H8: Social influence has a positive relationship with behavioural intention towards GC usage.

- H9: Effort expectancy has a positive relationship with behavioural intention towards GC usage.

- H10: Facilitating conditions has a positive relationship with behavioural intention towards GC usage.

- H12: Hedonic motivation has a positive relationship with behavioural intention towards GC usage.

- H13: Behavioural intention has a positive relationship with use behaviour towards GC usage.

\section{Performance expectancy, price value and moderating constructs}

In this model, some constructs were removed due to empirical findings in virtual learning environment and GC studies. For example, performance expectancy was removed due to the use of GC as a compulsory learning platform. Students are aware of the conditions and need to use GC as a mandatory learning platform where technical requirements to support these activities were planned and justified to achieve their learning goals. performance expectancy was also found not to influence behavioural intention for virtual learning environment adoption, where social influence has been a more substantial determining factor (Nicholas-Omoregbe et al., 2017).

Additionally, we also disregarded price value as GC is a free platform and students were not required to purchase any account to use GC. Furthermore, moderating constructs that are the users' demographic attributes such as gender, age, voluntariness and experience were not added to the model either. According to Efiloğlu Kurt and Tingöy (2017) and Moorthy et al. (2019), the omission of these constructs can be justified by considering the homogeneity of the sample. This includes the same age bracket, academic level and experiences. Next, the mandatory nature of using GC further eliminates the need to add the voluntary construct as a moderating variable. Lastly, we disregarded the gender perspective as it was not crucial in the overall objective of this study as also reported by Liebenberg et al. (2018). Therefore, we used the baseline model as suggested by Venkatesh et al. (2016) by omitting moderating effects and focusing on the main effects of the UTAUT2 constructs. The modified conceptual model for this study is presented in Figure 3. 


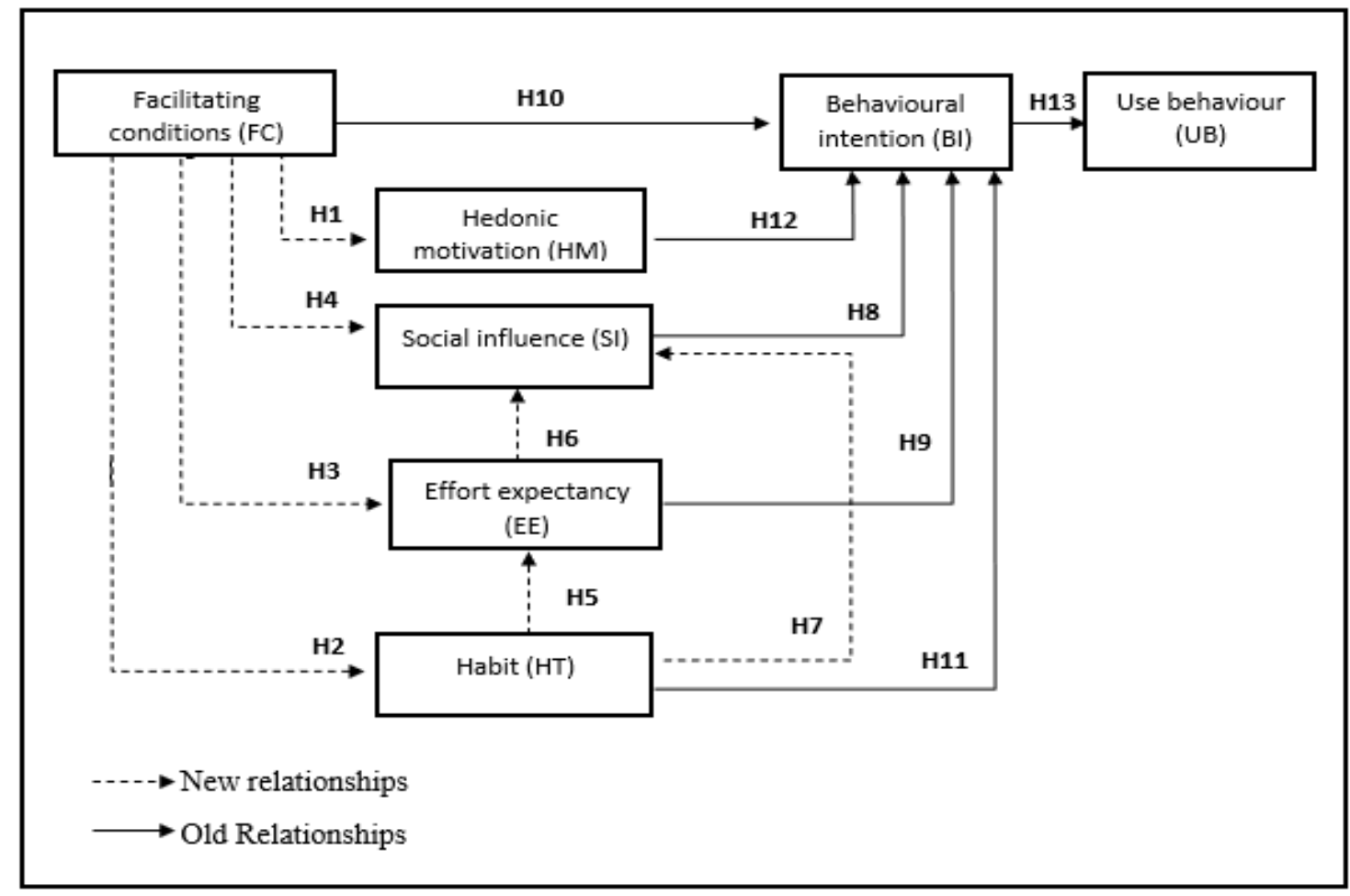

Figure 3. Conceptual model

\section{Methodology}

This study adopted a mixed-method approach based on an explanatory sequential design with the survey as the primary data collection method. In view of this, an online survey using Google forms was used to collect data based on purposive sampling from a population of 206 undergraduate students who were using GC. The respondents were directed to answer the online survey items only after completing the semester. The questionnaire used a 5-point Likert scale (strongly disagree $=1$; disagree $=2 ;$ neutral $=3$; agree $=4$; and strongly agree $=5$ ). The 26 items with two sections provided insights based on respondents' demographic attributes (gender, programme, year of study and mobile devices used to access the platform) and the main data variables (facilitating conditions, effort expectancy, hedonic motivation, habit, social influence, behavioural intention and use behaviour). Accordingly, due to ethical considerations, the respondents were fully informed about the purpose of the study, consequences, their rights to withdraw from the study and how the data will be used before partaking in the study. Furthermore, respondents' anonymity and confidentiality were also explained and added in the Google Forms.

The instrument was validated by experts' reviews and previous use as reported in Kumar and Bervell (2019). After this, a partial least squares (PLS) algorithm was used for confirmatory factor analysis. Those items that loaded below the 0.5 threshold were deleted. Out of the 216 undergraduate students, 163 of them provided complete responses to the online survey items. This represented about $75.46 \%$, which was sufficient for the study and adequately represented the total population (Krejcie \& Morgan, 1970). Thus, a sample of 163 out of 216 is a good representative sample. Data collected were exported to SPSS for cleaning and later converted into a comma-separated variable file and exported to Smart-PLS software for structural equation modelling analysis. Partial least squares structural equation modelling (PLS-SEM) was used to predict relationships that were hypothesised and not observed through latent variables (Hair et al., 2013). As for the qualitative component, a purposive sampling and saturation method were used to select eight participants to provide an in-depth explanation as a follow-up to the results from the quantitative structural model analysis (Creswell \& Clark, 2011). In view of that, specific questions were asked to validate and explain the outcome of the quantitative analysis. 


\section{Analysis and results}

The analyses for this study were divided into two: the demographic analysis and the model analysis.

\section{Demographic analysis}

The initial analysis was on the demographic data of students. Thus, students' representation in terms of gender, programme and study level were analysed based on descriptive statistics. The results are shown in Table 1.

Table 1

Demographic statistics of students

\begin{tabular}{lll}
\hline Demographic variables & Frequency $(N)$ & Percentage $(\%)$ \\
\hline Gender & 30 & 18.4 \\
Male & 133 & 81.6 \\
Female & & \\
Programme & 150 & 92 \\
$\quad$ Education & 13 & 8 \\
Humanities & 150 & 92 \\
Year of study & 11 & 6.7 \\
First year & 2 & 1.2 \\
Second year & 68 & 41.7 \\
Third year & 157 & 96.3 \\
Mobile devices used & 6 & 3.7 \\
$\quad$ Notebooks & & \\
Smartphones & & \\
iPads & &
\end{tabular}

Table 1 shows that more females participated than males. A clear disparity between 133 females compared to only 30 males confirms this representing $81.6 \%$ and $18.4 \%$ respectively. On the study programme, education students had the majority, namely 150 with a percentage of $92 \%$, while only eight students were from humanities. Additionally, the number of first-year students in this study far outweighed that of second and third years; that is, 150 first-year students compared to 11 and two for second- and third-year students respectively. Finally, mobile devices that students used to access the GC comprised 157 smartphones, 68 notebooks and only six iPads. This suggests that smartphones were primarily used to access GC in this study.

\section{Model analysis}

\section{Measurement model}

This study assessed the measurement model against parameter criteria based on running the initial PLS algorithm as depicted by Figure 4 with the corresponding measurements shown in Tables 2, 3 and 4 . As shown in Table 2, all loadings of the items across the various constructs were higher than the minimum 0.5 threshold (Hair et al., 2017) with the exception of Item 1 for use behaviour, which was 0.493. However, this item was retained because of content validity and also the fact that it did not deviate too much from the 0.5 recommended figure (Hair et al., 2017, Kline, 2015). Additionally, Cronbach's alpha values were all higher than 0.7, as recommended by Nunally et al. (2015). A further measurement of rho_A and composite reliability, which were above the 0.7 threshold, validated the reliability. Similarly, the summation of the items' squared loadings as the average of the number of items across the construct (AVE > 0.5) also showed sufficient co-efficient figures across all the constructs (Hair et al., 2017). 
Table 2

Internal consistency measures

\begin{tabular}{|c|c|c|c|c|c|}
\hline Variables & $\begin{array}{l}\text { Item } \\
\text { loadings }\end{array}$ & $\begin{array}{c}\text { Cronbach's } \\
\text { alpha }\end{array}$ & rho_a & $\begin{array}{c}\text { Composite } \\
\text { reliability }\end{array}$ & $\begin{array}{l}\text { Average variance } \\
\text { extracted (AVE) }\end{array}$ \\
\hline \multirow[t]{4}{*}{ Effort expectancy } & 0.866 & 0.855 & 0.862 & 0.902 & 0.698 \\
\hline & 0.860 & & & & \\
\hline & 0.759 & & & & \\
\hline & 0.852 & & & & \\
\hline \multirow[t]{3}{*}{ Facilitating conditions } & 0.842 & 0.803 & 0.803 & 0.884 & 0.717 \\
\hline & 0.854 & & & & \\
\hline & 0.844 & & & & \\
\hline \multirow[t]{3}{*}{ Hedonic motivation } & 0.890 & 0.871 & 0.873 & 0.921 & 0.794 \\
\hline & 0.884 & & & & \\
\hline & 0.899 & & & & \\
\hline \multirow[t]{4}{*}{ Habit } & 0.832 & 0.869 & 0.870 & 0.911 & 0.718 \\
\hline & 0.881 & & & & \\
\hline & 0.872 & & & & \\
\hline & 0.803 & & & & \\
\hline \multirow[t]{3}{*}{ Social influence } & 0.858 & 0.859 & 0.859 & 0.914 & 0.780 \\
\hline & 0.901 & & & & \\
\hline & 0.890 & & & & \\
\hline \multirow[t]{3}{*}{ Behavioural intention } & 0.853 & 0.835 & 0.836 & 0.901 & 0.752 \\
\hline & 0.896 & & & & \\
\hline & 0.853 & & & & \\
\hline \multirow[t]{2}{*}{ Use behaviour } & 0.493 & 0.715 & 0.711 & 0.700 & 0.561 \\
\hline & 0.938 & & & & \\
\hline
\end{tabular}

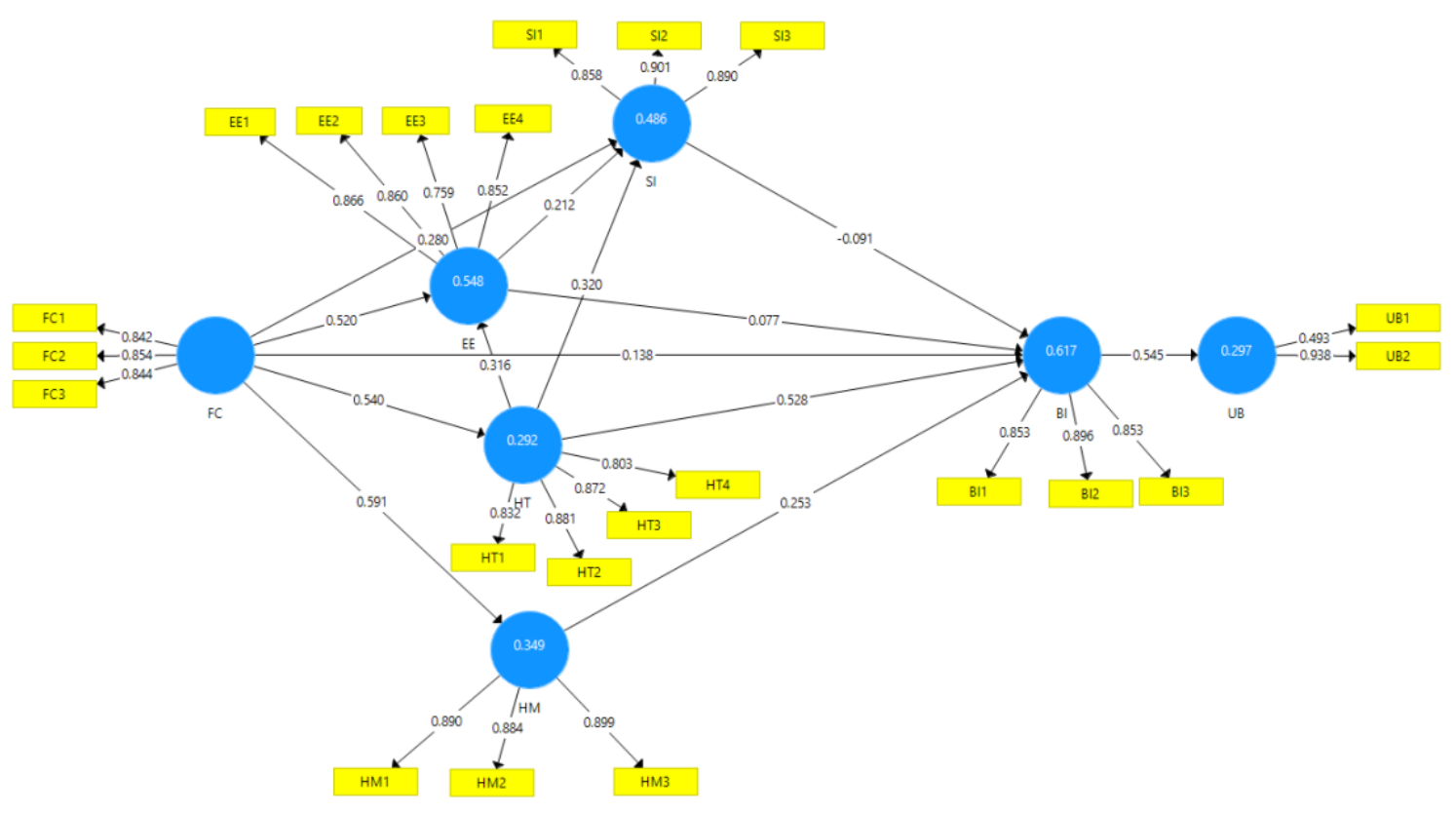

Figure 4. PLS algorithm 


\section{Discriminant validity}

Discriminant validity assesses the exclusiveness of all the constructs defined in a hypothesised model. Using a strict heterotrait-monotrait ratio criterion, this study ascertained each construct's uniqueness in the model (Table 3). As recommended by Henseler et al. (2015), all the heterotrait-monotrait values across the constructs in a model should not exceed 0.90 .

Table 3

Heterotrait-monotrait ratio values

\begin{tabular}{llllllll}
\hline Variables & BI & EE & FC & HM & HT & SI & UB \\
\hline BI & 0 & & & & & & \\
\hline EE & 0.719 & 0 & & & & & \\
\hline FC & 0.699 & 0.830 & 0 & & & & \\
\hline HM & 0.709 & 0.796 & 0.705 & 0 & & & \\
\hline HT & 0.836 & 0.689 & 0.643 & 0.562 & 0 & 0 & 0.691 \\
\hline SI & 0.550 & 0.689 & 0.721 & 0.513 & 0.590 & 0
\end{tabular}

Note. BI: behavioural intention, EE: effort expectancy, FC: facilitating conditions, HM: hedonic motivation, HT: habit, SI: social influence, UB: use behaviour

\section{Multicollinearity}

Collinearity assessment for reflective models is essential in eradicating type 1 and type 2 errors in path significance analyses (Hair et al., 2017). In order to verify for multicollinearity among constructs in a model, variance inflation factor (VIF) values are used (Kock, 2015). Table 4 shows the VIF values across the constructs. All VIF values were below the strict criterion of 3.3, as recommended by Kock (2015). Values ranged between a minimum of 1.000 to a maximum of 2.808, which suggests that the model is free from multicollinearity.

Table 4

Multicollinearity statistics

\begin{tabular}{|c|c|c|c|c|c|c|c|}
\hline Variables & $\mathrm{BI}$ & $\mathrm{EE}$ & $\mathrm{FC}$ & $\mathrm{HM}$ & HT & SI & UB \\
\hline BI & & & & & & & 1.000 \\
\hline $\mathrm{EE}$ & 2.808 & & & & & 2.213 & \\
\hline $\mathrm{FC}$ & 2.258 & 1.412 & & 1.000 & 1.000 & 2.011 & \\
\hline $\mathrm{HM}$ & 2.008 & & & & & & \\
\hline HT & 1.856 & 1.412 & & & & 1.634 & \\
\hline SI & 1.950 & & & & & & \\
\hline UB & & & & & & & \\
\hline
\end{tabular}

Note. BI: behavioural intention, EE: effort expectancy, FC: facilitating conditions, HM: hedonic motivation, HT: habit, SI: social influence, UB: use behaviour

\section{Structural model analysis}

Based on bootstrapping of 5000 resamples (Hair et al., 2017), the paths' significance results and the validated indicators are shown in Table 5, while the bootstrap image results are depicted in Figure 5. From Table 5, the predictors of behavioural intention in the model were hedonic motivation $(\beta=0.254, p=0.004$ at $p \leq 0.01)$ and habit $(\beta=0.526, p=0.000$ at $p \leq 0.01)$. Hedonic motivation and habit's significance in predicting behavioural intention were further validated by a unidimensional confidence interval of 0.099 to 0.413 and 0.407 to 0.637 respectively. This indicates the absence of spurious effect in the prediction based on the lower and upper boundary values at a $95 \%$ confidence level. On the contrary, effort expectancy $(\beta$ $=0.082, p=0.222$ at $p \geq 0.05)$, facilitating conditions $(\beta=0.131, p=0.064$ at $p \geq 0.05)$ and social influence $(\beta=-0.087, p=0.137$ at $p \geq 0.05)$ were insignificant in determining students' behavioural intention to use 
GC. These non-significant effects were proven further by the multidimensional nature of the confidence interval values based on the lower and upper boundaries.

Table 5

Model paths significance

\begin{tabular}{|c|c|c|c|c|c|c|c|}
\hline Hypotheses & $\begin{array}{c}\text { Beta } \\
\text { values }\end{array}$ & $\begin{array}{l}\text { Standard } \\
\text { deviation }\end{array}$ & T statistics & $p$ values & $\mathrm{f}^{2}$ & \multicolumn{2}{|c|}{$\begin{array}{c}\text { Confidence } \\
\text { interval } \\
5.0 \% 95.0 \%\end{array}$} \\
\hline H1: FC -> HM & 0.591 & 0.073 & $8.136^{*}$ & 0.000 & 0.536 & 0.466 & 0.705 \\
\hline H2: FC -> HT & 0.544 & 0.064 & $8.462 *$ & 0.000 & 0.412 & 0.438 & 0.645 \\
\hline H3: FC $->$ EE & 0.519 & 0.078 & $6.665^{*}$ & 0.000 & 0.424 & 0.383 & 0.643 \\
\hline $\mathrm{H} 4: \mathrm{FC}->\mathrm{SI}$ & 0.283 & 0.110 & $2.557^{*}$ & 0.005 & 0.076 & 0.108 & 0.468 \\
\hline H5: HT -> EE & 0.318 & 0.071 & $4.478^{*}$ & 0.000 & 0.157 & 0.200 & 0.433 \\
\hline H6: EE -> SI & 0.215 & 0.085 & $2.491 *$ & 0.006 & 0.039 & 0.070 & 0.348 \\
\hline H7: HT -> SI & 0.316 & 0.096 & $3.346^{*}$ & 0.000 & 0.122 & 0.157 & 0.470 \\
\hline H8: SI -> BI & -0.087 & 0.083 & 1.093 & 0.137 & 0.011 & -0.223 & 0.048 \\
\hline H9: EE -> BI & 0.082 & 0.100 & 0.766 & 0.222 & 0.006 & -0.076 & 0.255 \\
\hline H10: FC -> BI & 0.131 & 0.090 & 1.526 & 0.064 & 0.022 & -0.019 & 0.281 \\
\hline H11: HT -> BI & 0.526 & 0.070 & $7.514^{*}$ & 0.000 & 0.392 & 0.407 & 0.637 \\
\hline H12: HM -> BI & 0.254 & 0.094 & $2.682 *$ & 0.004 & 0.083 & 0.099 & 0.413 \\
\hline H13: BI -> UB & 0.552 & 0.057 & $9.540 *$ & 0.000 & 0.423 & 0.456 & 0.646 \\
\hline
\end{tabular}

$* p \leq 0.01$

Note. BI: behavioural intention, EE: effort expectancy, FC: facilitating conditions, HM: hedonic motivation, HT: habit, SI: social influence, UB : use behaviour

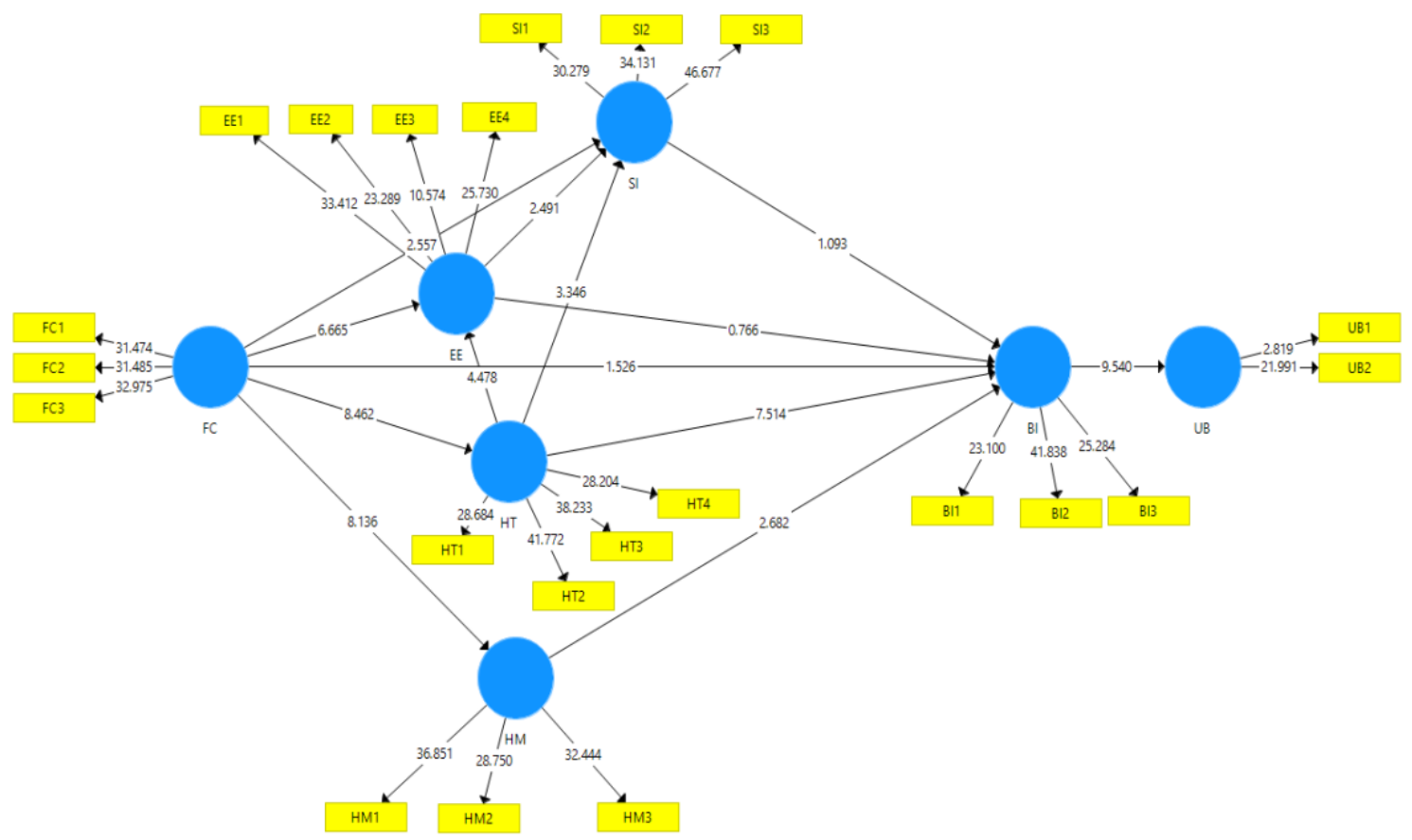

Figure 5. Bootstrap image for path significance

However, facilitating conditions was found to determine effort expectancy $(\beta=0.519, p=0.000$ at $p \leq$ $0.01)$, hedonic motivation $(\beta=0.591, p=0.000$ at $p \leq 0.01)$, habit $(\beta=0.544, p=0.000$ at $p \leq 0.01)$ and social influence $(\beta=0.283, p=0.005$ at $p \leq 0.01)$. Furthermore, effort expectancy $(\beta=0.215, p=0.006$ at $p \leq 0.01)$ and habit $(\beta=0.316, p=0.000$ at $p \leq 0.01)$ both determined social influence of students towards 
GC. Additionally, habit determined effort expectancy at $(\beta=0.318, p=0.000$ at $p \leq 0.01)$. Finally, behavioural intention of students towards GC significantly determined their actual use behaviour of GC $(\beta$ $=0.552, p=0.000$ at $\mathrm{p} \leq 0.01)$. All the significant path relationships had a one-dimensional pattern representing their confidence intervals' lower and upper boundaries and confirming a non-spurious effect. With regards to the magnitude of the predictions, the effect sizes $\left(\mathrm{f}^{2}\right)$ ranged from a minimum of 0.02 to a maximum of 0.536. Based on the range of figures from Table 1, the effects of the significant paths ranged from small, medium to large sizes. However, most of the effects for the significant paths were medium to large. Hair et al. (2017) confirmed this, and Cohen (1988) stated that effect sizes of 0.02, 0.15 and 0.35 (such as those above) indicate small, medium and large significant effects respectively.

\section{Indirect and mediation effects of habit and hedonic motivation on facilitating conditions towards behavioural intention}

Further analysis on why facilitating conditions was insignificant in predicting behavioural intention was done through indirect and mediation analyses. The results are reported in Table 6 . The indirect paths showed that facilitating conditions effects behavioural intention indirectly via routes through habit and hedonic motivation towards behavioural intention. This was further proven by the significance of the mediation effects of habit and hedonic motivation on facilitating conditions in predicting behavioural intention. Therefore, the total effect of facilitating conditions on behavioural intention was completely absorbed by the full mediation of habit and hedonic motivation, which are validated by the unidimensional nature of the confidence intervals at a level of $95 \%$.

Table 6

Indirect and mediation effects of habit and hedonic motivation on facilitating conditions towards behavioural intention

\begin{tabular}{lcccccc}
\hline $\begin{array}{l}\text { Indirect/mediation } \\
\text { paths }\end{array}$ & $\begin{array}{c}\text { Beta } \\
\text { values }\end{array}$ & $\begin{array}{c}\text { Standard } \\
\text { deviation }\end{array}$ & $t$ statistics & $p$ values & \multicolumn{2}{c}{ Confidence interval } \\
\cline { 5 - 7 } & & & & & $5.0 \%$ & $95.0 \%$ \\
\hline FC $->$ HM->BI & 0.149 & 0.063 & $2.364^{*}$ & 0.009 & 0.055 & 0.263 \\
FC -> HT->BI & 0.285 & 0.049 & $5.798^{*}$ & 0.000 & 0.208 & 0.368 \\
\hline
\end{tabular}

$* p \leq 0.01$

Note. BI: behavioural intention, FC: facilitating conditions, HM: hedonic motivation, HT: habit

Coefficient of determination $\left(R^{2}\right)$

The coefficient of determination further strengthens the confidence of predicting the exogenous variables on their endogenous counterparts. The results of the total variance explained by the various predictions of the endogenous variables are shown by Table 7 . The implication is that the model explained $61.7 \%$ in variance for behavioural intention towards the use of GC. This total variance explained by the model is relatively large as indicated by Hair et al. (2013) who suggested values of $0.25,0.5$ and 0.7 as small, medium and large. The $\mathrm{R}^{2}$ values for prediction variance in social influence $(0.486)$ and hedonic motivation (0.349) were closer to the medium threshold while effort expectancy (0.548) was above the medium parameter. However, the variance explained in use behaviour (0.297) and habit (0.292) were relatively small because only one exogenous variable determined them. For instance, the total variance explained in use behaviour was determined only by behavioural intention, while facilitating conditions determined only habit.

Table 7

Coefficient of determination for significant paths

\begin{tabular}{lll}
\hline Variable & $\mathrm{R}^{2}$ & $\mathrm{R}^{2}$ (adjusted) \\
\hline Behavioural intention & 0.617 & 0.605 \\
Effort expectancy & 0.548 & 0.543 \\
Hedonic motivation & 0.349 & 0.345 \\
Habit & 0.292 & 0.288 \\
Social influence & 0.486 & 0.476 \\
Use behaviour & 0.297 & 0.293 \\
\hline
\end{tabular}




\section{Qualitative findings}

The qualitative method was used to explain the quantitative analysis's insignificant findings while validating significant relationships (Creswell \& Clark, 2011) between facilitating conditions with effort expectancy, habit, social influence and hedonic motivation. The quantitative analysis indicated three insignificant relationships between facilitating conditions and behavioural intention, social influence and behavioural intention and effort expectancy and behavioural intention. As the study focused on facilitating conditions, we questioned students on their perceptions of how facilitating conditions influences GC use based on open-ended questions using Google Forms. The six questions focused on their perceptions of how facilitating conditions influenced their use of GC regarding benefits, motivation, social learning and their overall goal of using GC as a learning tool.

According to the respondents, while facilitating conditions did provide easy alternatives to accessing and managing learning content, the use of GC, while being habitual due to prior use also provided a mobilebased alternative to online learning. An example of respondents' feedback is "Google Classroom can be accessed using various devices and it is convenient to use as most of us have a Gmail account." As Google's use has become habitual, it stands as a facilitating condition that influences behaviour as respondents express how it is familiar and effortless to use Gmail and Google Cloud for teaching and learning. One respondent explained that:

Google Classroom is an app under Google. The same goes for Gmail and Google Drive. Since these apps are linked to Google, it's easier to access them in Google Classroom. I log in to my Gmail to enter Google Classroom. I store my assignments in Google Drive provided in the Google Classroom.

Conversely, for facilitating conditions and social influence, respondents had a positive perception of the support they received from their instructor and peers. For example, one respondent claimed that they learnt a lot about operating GC with the help of their peers, stating that "Sometimes when I have issues in submitting, I do get the help of my friends. I learn a lot from my friends in how to use Google Classroom". At the same time, another student responded, "The lecturer did facilitate us by helping us to communicate with the other students and with the lecturer herself through the platform." Furthermore, a significant positive relationship between facilitating conditions and hedonic motivation was also supported as students enjoyed using Google applications to meet their learning goals. As an example, we observed students expressing how the ease of use, security and centrality of Google applications with GC created a pleasurable experience such as "everything is automatically saved in your Gmail account. Just log in and everything is there," while another student claimed, "I feel more motivated to use the platform as there is support from my instructor."

Next, we also observed that respondents indicated that they used the system solely to achieve their learning goals and their intention was mainly to complete the learning task. One respondent stated, "I am not an avid user ... unless needed," whereas another stated, "I get to experience how to use google classroom myself and I always look at YouTube videos to learn more about the online learning platforms. So, my own experience is the main influencing factor". Such feedback indicated why facilitating conditions had an insignificant relationship with behavioural intention. Furthermore, this also shows why social influence had an insignificant relationship with behavioural intention. In addition, respondents indicated that the learnability of the system is dependent on the student's capability for self-discovery. For example, one student described GC as a "self-learning tool," while another described displeasure by stating: "the lecturer expects every student to know how to use Google Classroom." Lastly and interestingly, ease of use was not found to define behavioural intention and based on the feedback received, we noticed habit had a highly influential role which promoted automaticity in use. The majority of students indicated that the use of Google applications was habitual and overshadowed their easiness perception. As an example, one respondent stated, "Yes...we all use Google for almost everything and using Google Classroom relates to everything easily". 


\section{Discussion}

This study has differentiated itself from the general acceptance studies of GC research by focusing on how facilitating conditions as an exogenous variable influences other factors leading to behavioural intention. The outcome of the study indicates that the determinants of behavioural intention towards GC acceptance were mainly hedonic motivation and habit but not facilitating conditions, as also reported by Jakkaew and Hemrungote (2017), Kumar and Bervell (2019) and De Campos et al. (2019). This perspective is underpinned by the fact that the enjoyment in using GC culminates into a motivation that defines favourable psychological acceptance formations. Furthermore, habitual tendencies also propel students' positive cognitive orientations towards GC, as reflected in the interview responses on the familiarity with using Google applications. Extensive use of GC has rendered familiarity and easiness towards usage as a result of experience settling in after copious usage (Kumar et al., 2020; Venkatesh et al., 2008). Hence, the effect of facilitating conditions on behavioural intention became insignificant, as also observed by Venkatesh et al. (2003) and Maruping et al. (2017), who claimed that the facilitating conditions relationship with behavioural intention was masked by factors such as effort expectancy and social influence. However, as effort expectancy and social influence also did not directly influence behavioural intention, we speculate that the outcome was due to the mandatory use of GC for teaching and learning. Effort expectancy's insignificance on behavioural intention is also accentuated by other studies such as those from Salloum and Shaalan (2019) and Ahmad et al. (2020). Additionally, when students perceive that a platform is easy to use, facilitating conditions surrounding usage becomes neglectable as they will adapt towards obtaining resources to facilitate the use of the technology. Statistically, the non-significance of the direct effect of facilitating conditions on behavioural intention is explained by the total absorption of the mediation effects of both habit and hedonic motivation towards behavioural intention. The insignificance of facilitating conditions on behavioural intention for GC acceptance is reflective of other GC studies (Kumar \& Bervell, 2019; Raman \& Rathakrishnan, 2020) and information system studies (Meyliana et al., 2019). Furthermore, UTAUT's proposition of facilitating conditions relates to external factors, which is distinct from the proposition of behavioural intention as an internal factor (Venkatesh et al., 2008). Maruping et al. (2017) and Venkatesh et al. (2003) noted the above incongruity as a reason why facilitating conditions was justified as not predicting behavioural intention.

Similarly, effort expectancy and social influence did not directly affect behavioural intention and also did not operate as mediating factors between facilitating conditions and behavioural intention within this study. Ajzen (1985) described behavioural intention as a factor that has limited predicting capabilities of any selfimposed behaviour which is similar to the use of GC for teaching and learning. With respect to social influence, since students were experienced in using GC, the social effect of referent others did not influence psychological intention formations (Arain et al., 2019; Chávez Herting et al., 2020; Meyliana et al., 2019). Maruping et al. (2017) explained that both social influence and facilitating conditions are related to external factors and are better predictors of BE than behavioural intention. In addition, through the interviews, respondents claimed that they did not receive the support needed to adopt GC as the instructors assumed that they had experiences using the system. The support needed was obtained from peers and through selfdiscovery. Nevertheless, Internet accessibility, mobile access and instructor support for collaborative and communication activities rather explain the positive relationship between facilitating conditions and social influence.

The main contribution of this study is that it has revealed the role of facilitating conditions in indirectly predicting behavioural intention through habit and hedonic motivation. These findings are novel and vital because habit and hedonic motivation were the only two factors that predicted behavioural intention towards GC, hence indicating facilitating conditions as a precursor to habit and hedonic motivation. These findings also suggest that habit and hedonic motivation provide full mediation within which the relationship between facilitating conditions and behavioural intentions becomes indirect. This indirect relationship between facilitating conditions and behavioural intention is supportive of Maruping et al.'s (2017) depiction of UTAUT facilitating conditions as representing external facets rather than internal facets, which are instrumental in determining behavioural intention. Most importantly within this study, facilitating conditions promoted hedonic motivation and enabled habitual uptake of GC. Facilities such as the Internet, teacher pedagogical support, technical support, ownership of smartphone devices and user interaction became a positive behavioural control. This is because they strongly determined the habit and hedonic motivation of students regarding GC usage. According to Moghavvemi et al. (2017), online learners tend to emphasise hedonic aspects compared to easiness of systems. The positive relationships between 
facilitating conditions, habit and hedonic motivation stipulate that facilitating conditions drives enjoyment and habitual formations. Thus, enabling resources in place for GC usage correspond to rendering GC's use to be undemanding from students' perspectives and further promotes easiness of use (Saeed Al-Maroof et al., 2021). This relationship is supported by other studies on system acceptance, such as by Zainol et al. (2017) and Kumar and Bervell (2019). Similarly, effort expectancy instils a positive social influence on students' GC usage (Bervell \& Umar, 2017; Mensah, 2019). Furthermore, this study has expounded that when GC usage becomes habitual, it will inculcate a positive social influence mediated through ease of use towards GC as a virtual learning environment as reflected by a significant positive relationship between habit with effort expectancy and habit with social influence. This finding favours that of Limayem et al. (2007), who also indicated that habit formation towards system usage determined a positive social influence among users. Based on the interviews, respondents explained that the habitual use of Google applications and the simplicity of their interaction to facilitate the use of GC was fundamental in promoting GC as a practical learning tool among themselves.

Finally, the study revealed a significant positive relationship between behavioural intention and use behaviour, which was also the strongest relationship in the model. Empirical studies on GC such as those from Jakkaew and Hemrungrote (2017) as well as Saeed Al-Maroof and Al-Emran (2018) have obtained a significant predictive relationship between behavioural intention and use behaviour. Venkatesh et al. (2003) and Yousafzai et al. (2010) argued that once usage intentions are formed towards a particular behaviour, it will automatically lead to the performance of the actual behaviour which was confirmed in this study. According to Salloum and Shaalan (2019), this relationship between behavioural intention and use behaviour has been consistent across most system acceptance studies, and GC is no exception. In terms of variance explained by the model, we compared our findings to the initial findings as reported by Kumar and Bervell (2019) and found that the total variance explained by behavioural intention reduced from $63.1 \%$ to $60.5 \%$ and for use behaviour from $70.5 \%$ to $29.3 \%$. This could be attributed to the fact facilitating conditions played a role as the key exogenous variable in the model. Furthermore, the variance explained in use behaviour $(29.7 \%)$ and habit $(29.2 \%)$ was relatively small. The reason could be the presence of a single predictor variable for each. For use behaviour, considering other factors such as integrating behavioural expectations can explain a higher level of variance (Venkatesh et al., 2008) as it is the strongest predictor of use through social influence and facilitating conditions (Maruping et al., 2017). As for habit's small, predicted variance, having facilitating conditions as the only predictor accounted for habitualisation, and this provides a basis to find out whether habit as a behaviour could also be influenced by pleasure, frequency of use and extensiveness of use (Limayem et al., 2007). It is worth noting that constructs with small predictive variance are an indication that other constructs should be added to further improve upon the predictive variance within the model. We advocate this as critical, as the model may provide sufficient explanation for behavioural intention but not for use behaviour. Irrespective of that, the findings are congruent with the interview feedback as GC is used solely by students to achieve their learning goals and where the use of GC is mandatory rather than voluntary. Based on the findings provided by this study, it is apt to indicate that for students to commit to continuously using GC, which is denoted by use behaviour, policies and supports from higher education organisations are fundamental.

\section{Implications for theory}

Modelling the exclusive effects of facilitating conditions on the other exogenous variables leading to behavioural intention and use behaviour for GC usage is imperative for unearthing the significance of this variable in acceptance models of educational online learning systems. Most importantly, the influence of facilitating conditions on hedonic motivation, habit and effort expectancy are crucial findings that need inclusion in acceptance models on virtual learning systems for further validation. Finally, emphasising the relationship between facilitating conditions and social influence in an acceptance model is essential as it partly explains the influence of learning communities, especially for social-collaborative learning in moderating online learning intention.

\section{Implications for policy and practice}

This study has unveiled that the two most important determinants for behavioural intention towards GC as a virtual learning environment in higher education are hedonic motivation and habit. This implies that efforts should be made by higher education institutions that want to implement GC as a virtual learning environment to create the environment needed for motivation and enjoyment of students towards the use 
of GC. These are quintessential in creating habitual use of GC. However, the precursor for hedonic motivation, habit and effort expectancy are the facilitating conditions made available and accessible towards GC usage as a virtual learning environment. Such resources as the Internet, access gadgets and technical and pedagogical support are imperative towards rendering habitual and pleasant interaction towards GC use intentions. We also add that promoting the affordances of mobile learning and possession of smartphones influence students' habitual use of GC platforms.

\section{Limitations and recommendations for future studies}

The study was limited to only higher education students without the perspectives of lecturers. The use of GC for lecturers in higher education is subjective as there is a high preference for using the institution's official learning management system or virtual learning environment. Future studies could capture lecturers' views or even make it a unified study on students' and lecturers' perspectives. Additionally, the study did not assess the relationship between facilitating conditions and use behaviour, effort expectancy and hedonic motivation and between hedonic motivation and habit. Thus, future studies could include these relationships in the model. Furthermore, performance expectancy was excluded but may have contributed to the total variance explained by the model and should be considered for inclusion in future studies. In addition, another perspective to be considered is based on utilitarian needs such as effectiveness, usefulness, necessity and practicality, which may account for better prediction of behavioural intention and use behaviour. Furthermore, due to the importance of hedonic motivation and habit in this study, the hedonicmotivation system adoption model, where effort expectancy and performance expectancy are used as moderators that influence online learning (Lowry et al., 2013) and behavioural expectation (Maruping et al., 2017) may be considered to explain the acceptance of GC. Finally, no moderators were evaluated in terms of the significant paths of facilitating conditions effects on the other exogenous variables to verify for direction and incidence of the effects on specific demographic variables such as gender, programme or gadgets used for access. Similarly, not all the indirect, total and mediation effects were addressed in this study.

\section{Conclusion}

This study contributes to knowledge by modelling the exclusive effects of facilitating conditions on exogenous variables that lead to behavioural intention and use behaviour towards GC for online learning. It has revealed that the role of facilitating conditions as a precursor for habit and hedonic motivation is necessary for the uptake of GC as a virtual learning environment. Although facilitating conditions had a significant positive relationship with effort expectancy, social influence, hedonic motivation and habit, it did not directly predict behavioural intention. Additionally, the study has proven that for positive peer influence to prevail towards GC, habit, effort expectancy and facilitating conditions are necessary factors to consider. Nevertheless, social influence and effort expectancy were not significant in indicating behavioural intention as GC's use was mandatory. In addition, even though facilitating conditions was insignificant in determining behavioural intention towards GC usage in this study, it only confirmed earlier postulations in UTAUT and UTAUT2 that the effect of facilitating conditions is rather more directly on actual use behaviour. Finally, this study has proven that the insignificant direct effect of facilitating conditions on behavioural intention was as a result of the full mediation of the total effects of habit and hedonic motivation on facilitating conditions towards behavioural intention.

\section{References}

Abazi-Bexheti, L., Kadriu, A., Apostolova-Trpkovska, M., Jajaga, E., \& Abazi-Alili, H. (2018). LMS solution: Evidence of Google Classroom usage in higher education. Business Systems Research, 9(1), 31-43. https://doi.org/10.2478/bsrj-2018-0003

Ahmad, T. S. A. S., Ramlan, Z. S., \& Krishnan, S. K. (2020). Acceptance of Google Classroom for learning English exit test. International Journal of Modern Languages and Applied Linguistics, 4(1), 67-76. https://doi.org/10.24191/ijmal.v4i1.9504

Ain, N. U., Kaur, K., \& Waheed, M. (2016). The influence of learning value on learning management system use: An extension of UTAUT2. Information Development, 32(5), 1306-1321. https://doi.org/10.1177/0266666915597546 
Ajzen, I. (1985). From intentions to actions: A theory of planned behavior. In J. Kuhl \& J. Beckmann (Eds.), SSSP Springer Series in social psychology. Action control: From cognition to behavior (pp. 11-39). Springer. https://doi.org/10.1007/978-3-642-69746-3_2

Alia, S., \& Hamtini, T. (2019). Designing and implementing an e-Course using Adobe Captivate and Google Classroom: A case study. In Proceedings of the 2019 2nd International Conference on New Trends in Computing Sciences (pp.1-6). IEEE. https://doi.org/10.1109/ICTCS.2019.8923037

Ansong-Gyimah, K. (2020). Students' perceptions and continuous intention to use e-learning systems: The case of Google Classroom. International Journal of Emerging Technologies in Learning, 15(11), 236-244. https://doi.org/10.3991/ijet.v15i11.12683

Arain, A. A., Hussain, Z., Rizvi, W. H., \& Vighio, M. S. (2019). Extending UTAUT2 toward acceptance of mobile learning in the context of higher education. Universal Access in the Information Society, 18(3), 659-673. https://doi.org/10.1007/s10209-019-00685-8

Assensoh-Kodua, A., \& Ngwane, K. K. V. (2015). Habit as a moderator and exogenous predictor of social networks: the case of online social networking. Journal of Governance and Regulation, 4(4), 354-363. https://doi.org/10.22495/jgr_v4_i4_c2_p8

Awang, H., Aji, Z. M., Osman, W. R. S., Nasir, A. A., Deli, M. M., \& Hamat, W. Y. W. (2019). Virtual Learning Environment (VLE) implementation strategy: An analysis of practicality for Google Classroom implementation in Malaysian schools. Journal of Educational Research and Indigeneous Studies, 2(2), 1-16.

Awang, H., Aji, Z. M., Yaakob, M. F. M., Osman, W. R. S., Mukminin, A., \& Habibi, A. (2018). Teachers' intention to continue using virtual learning environment (VLE): Malaysian context. Journal of Technology and Science Education, 8(4), 439-452. https://doi.org/10.3926/jotse.463

Barari, N., RezaeiZadeh, M., Khorasani, A., \& Alami, F. (2020). Designing and validating educational standards for E-teaching in virtual learning environments (VLEs), based on revised Bloom's taxonomy. Interactive Learning Environments, 1-13. https://doi.org/10.1080/10494820.2020.1739078

Bazelais, P., Doleck, T., \& Lemay, D. J. (2018). Investigating the predictive power of TAM: A case study of CEGEP students' intentions to use online learning technologies. Education and Information Technologies, 23(1), 93-111. https://doi.org/10.1007/s10639-017-9587-0

Beaumont, K. (2018). Google Classroom: An online learning environment to support blended learning. Compass: Journal of Learning and Teaching, 11(2). https://doi.org/10.21100/compass.v11i2.837

Bervell, B., \& Umar, I. N. (2017). Validation of the UTAUT model: Re-considering non-linear relationships of exogeneous variables in higher education technology acceptance research. Eurasia Journal of Mathematics, Science and Technology Education, 13(10), 6471-6490. https://doi.org/10.12973/ejmste/78076

Chávez Herting, D., Cladellas Pros, R., \& Castelló Tarrida, A. (2020). Habit and social influence as determinants of PowerPoint use in higher education: A study from a technology acceptance approach. Interactive Learning Environments, 1-17. https://doi.org/10.1080/10494820.2020.1799021

Chen, L., \& Aklikokou, A. K. (2020). Determinants of e-government adoption: Testing the mediating effects of perceived usefulness and perceived ease of use. International Journal of Public Administration, 43(10), 850-865. https://doi.org/10.1080/01900692.2019.1660989

Creswell, J. W., \& Clark, P. L. (2011). Designing and conducting mixed methods research (2nd ed.). Sage Publications.

Davis, F. D. (1989). Perceived usefulness, perceived ease of use, and user acceptance of information technology. MIS Quarterly, 13, 319-340. https://doi.org/10.2307/249008

de Campos Filho, A. S., de Souza Fantini, W., Ciriaco, M. A., dos Santos, J., Moreira, F., \& Gomes, A. S. (2019). Health student using google classroom: satisfaction analysis. In S. Uden, L. Liberona, D. Sanchez, \& G. Rodríguez-González (Eds.), Communications in computer and information science: Vol. 1011. Learning technology for education challenges (pp. 58-66). Springer. https://doi.org/10.1007/978-3-030-20798-4_6

Efiloğlu Kurt, Ö., \& Tingöy, Ö. (2017). The acceptance and use of a virtual learning environment in higher education: An empirical study in Turkey, and the UK. International Journal of Educational Technology in Higher Education, 14(26), 1-15. https://doi.org/10.1186/s41239-017-0064-Z

Eraslan Yalcin, M., \& Kutlu, B. (2019). Examination of students' acceptance of and intention to use learning management systems using extended TAM. British Journal of Educational Technology, 50(5), 2414-2432. https://doi.org/10.1111/bjet.12798

Hair, J. F., Ringle, C. M., \& Sarstedt, M. (2013). Partial least squares structural equation modeling: rigorous applications, better results and higher acceptance. Long Range Planning: International Journal of Strategic Management, 46(1-2), 1-12. https://doi.org/10.1016/j.lrp.2013.01.001 
Hair, J. F. Jr, Sarstedt, M., Ringle, C. M., \& Gudergan, S. P. (2017). Advanced issues in partial least squares structural equation modeling. SAGE Publications.

Hamutoglu, N. B., Gemikonakli, O., Duman, I., Kirksekiz, A., \& Kiyici, M. (2019). Evaluating students experiences using a virtual learning environment: satisfaction and preferences. Educational Technology Research and Development, 68(1), 437-462. https://doi.org/10.1007/s11423-019-09705-Z

Heggart, K. R., Yoo, J., \& Heggart, K. R. (2018). Getting the most from Google Classroom: A pedagogical framework for tertiary educators. Australian Journal of Teacher Education, 43(3), 140153. https://doi.org/10.14221/ajte.2018v43n3.9

Henseler, J., Ringle, C. M., \& Sarstedt, M. (2015). A new criterion for assessing discriminant validity in variance-based structural equation modeling. Journal of The Academy of Marketing Science, 43(1), 115-135. https://doi.org/10.1007/s11747-014-0403-8

Huang, F., Teo, T., \& Scherer, R. (2020). Investigating the antecedents of university students' perceived ease of using the Internet for learning. Interactive Learning Environments, 1-17. https://doi.org/10.1080/10494820.2019.1710540

Iftakhar, S. (2016). Google Classroom: What works and how? Journal of Education and Social Sciences, 3, 12-18. https://www.jesoc.com/wp-content/uploads/2016/03/KC3 35.pdf

Jakkaew, P., \& Hemrungrote, S. (2017). The use of UTAUT2 model for understanding student perceptions using Google Classroom: A case study of Introduction to Information Technology course. In Proceedings of the 2017 International Conference on Digital Arts, Media and Technology (pp. 205-209). Institute of Electrical and Electronics Engineers. http://doi.org/10.1109/icdamt.2017.7904962

Jordan, M. M., \& Duckett, N. D. (2018). Universities confront 'tech disruption': Perceptions of student engagement online using two learning management systems. The Journal of Public and Professional Sociology, 10(1), Article 4. https://digitalcommons.kennesaw.edu/jpps/vol10/iss 1/4

Khechine, H., Raymond, B., \& Augier, M. (2020). The adoption of a social learning system: Intrinsic value in the UTAUT model. British Journal of Educational Technology, 51(6), 2306-2325. https://doi.org/10.1111/bjet.12905

Kock, N. (2015). Common method bias in PLS-SEM: A full collinearity assessment approach. International Journal of e-Collaboration, 11(4), 1-10. https://doi.org/10.4018/ijec.2015100101

Kumar, J. A, \& Bervell, B. (2019). Google Classroom for mobile learning in higher education: Modelling the initial perceptions of students. Education and Information Technologies, 24, 1793-1817. https://doi.org/10.1007/s10639-018-09858-z

Kumar, J. A., Bervell, B., Annamalai, N., \& Osman, S. (2020). Behavioral intention to use mobile learning: Evaluating the role of self-efficacy, subjective norm, and WhatsApp use habit. IEEE Access, 8, 208058-208074. https://doi.org/10.1109/ACCESS.2020.3037925

Kumar, J. A., Bervell, B., \& Osman, S. (2020). Google classroom: insights from Malaysian higher education students' and instructors' experiences. Education and Information Technologies, 25(5), 4175-4195. https://doi.org/10.1007/s10639-020-10163-x

Liebenberg, J., Benade, T., \& Ellis, S. (2018). Acceptance of ICT: applicability of the unified theory of acceptance and use of technology (UTAUT) to South African Students. The African Journal of Information Systems, 10(3), Article 1. https://digitalcommons.kennesaw.edu/ajis/vol10/iss3/1

Limayem, M., \& Cheung, C. M. K. (2011). Predicting the continued use of Internet-based learning technologies: The role of habit. Behaviour and Information Technology, 30(1), 91-99. https://doi.org/10.1080/0144929X.2010.490956

Limayem, M., Hirt, S. G., \& Cheung, C. M. K. (2007). How habit limits the predictive power of intention: the case of information systems continuance. MIS Quarterly, 31(4), 705-737. https://doi.org/10.2307/25148817

Liu, H., Lin, C. H., Zhang, D., \& Zheng, B. (2018). Chinese language teachers' perceptions of technology and instructional use of technology: A path analysis. Journal of Educational Computing Research, 56(3), 396-414. https://doi.org/10.1177/0735633117708313

Lowry, P., Gaskin, J., Twyman, N., Hammer, B., \& Roberts, T. (2013). Taking "fun and games" seriously: Proposing the hedonic-motivation system adoption model (HMSAM). Journal of the Association for Information Systems, 14(11), 617-671. https://doi.org/10.17705/1 jais.0034

Madhavi, B. K., Mohan, V., \& Nalla, D. (2018). Improving attainment of graduate attributes using Google Classroom. Journal of Engineering Education Transformations, 31(3), 200-205. http://journaleet.in/index.php/jeet/article/view/120792/82931 
Maruping, L. M., Bala, H., Venkatesh, V., \& Brown, S. A. (2017). Going beyond intention: Integrating behavioral expectation into the unified theory of acceptance and use of technology. Journal of the Association for Information Science and Technology, 68(3), 623-637. https://doi.org/10.1002/asi.23699

Mensah, I. K. (2019). Factors influencing the intention of university students to adopt and use egovernment services: An empirical evidence in China. SAGE Open, 9(2), 1-19. https://doi.org/10.1177/2158244019855823

Meyliana, Widjaja, H. A. E., Santoso, S. W., Petrus, S., Jovian, \& Jessica. (2019). The enhancement of learning management system in teaching learning process with the UTAUT2 and trust model. In Proceedings of 2019 International Conference on Information Management and Technology (pp. 309-313). Institute of Electrical and Electronics Engineers. http://doi.org/10.1109/icimtech.2019.8843828

Moghavvemi, S., Paramanathan, T., Rahin, N. M., \& Sharabati, M. (2017). Student's perceptions towards using e-learning via Facebook. Behaviour and Information Technology, 36(10), 1081-1100. https://doi.org/10.1080/0144929X.2017.1347201

Moorthy, K., Tzu Yee, T., Chun T'ing, L., \& Vija Kumaran, V. (2019). Habit and hedonic motivation are the strongest influences in mobile learning behaviours among higher education students in Malaysia. Australasian Journal of Educational Technology, 35(4), 174-191. https://doi.org/10.14742/ajet.4432

Nicholas-Omoregbe, O. S., Azeta, A. A., Chiazor, I. A., \& Omoregbe, N. (2017). E-learning management system: A case of selected private universities in Nigeria. Turkish Online Journal of Distance Education, 18(2), 106-121. https://doi.org/10.17718/tojde.306563

Ohei, K. N., \& Brink, R. (2019). A framework development for the adoption of information and communication technology web technologies in higher education systems. South Africa Journal of Information Management, 21(1), 1-12. https://doi.org/10.4102/sajim.v21i1.1030

Rahmad, R., Adria Wirda, M., Berutu, N., Lumbantoruan, W., \& Sintong, M. (2019). Google classroom implementation in Indonesian higher education. Journal of Physics: Conference Series, 1175(1), 1-6. https://doi.org/10.1088/1742-6596/1175/1/012153

Raman, A., \& Rathakrishnan, M. (2020). Blended learning via Google Classroom: English language students experience based on UTAUT model and flow theory. Hamdard Islamicus, XLIII(1).

Rejón-Guardia, F., Polo-Peña, A. I., \& Maraver-Tarifa, G. (2020). The acceptance of a personal learning environment based on Google apps: The role of subjective norms and social image. Journal of Computing in Higher Education, 32(2), 203-233. https://doi.org/10.1007/s12528-019-09206-1

Saeed Al-Maroof, R., \& Al-Emran, M. (2018). Students acceptance of Google Classroom: An exploratory study using PLS-SEM approach. International Journal of Emerging Technologies in Learning, 13(06), 112-123. https://doi.org/10.3991/ijet.v13i06.8275

Saeed Al-Maroof, R., Alhumaid, K., \& Salloum, S. (2020). The continuous intention to use e-learning, from two different perspectives. Education Sciences, 11(1), Article 6. https://doi.org/10.3390/educsci11010006

Salloum, S. A., \& Shaalan, K. (2019). Factors affecting students' acceptance of e-learning system in higher education using UTAUT and structural equation modeling approaches. In A. E. Hassanien, F. M. Tolba, K. Shaalan, \& A. T. Azar (Eds.), Proceedings of the International Conference on Advanced Intelligent Systems (Vol. 2, pp. 469-480). Springer.

Scherer, R., Siddiq, F., \& Tondeur, J. (2019). The technology acceptance model (TAM): A meta-analytic structural equation modeling approach to explaining teachers' adoption of digital technology in education. Computers and Education, 128(0317), 13-35.

https://doi.org/10.1016/j.compedu.2018.09.009

Shaharanee, I. N. M, Jamil, J. M., \& Rodzi, S. S. M. (2016). The application of Google Classroom as a tool for teaching and learning. Journal of Telecommunication, Electronic and Computer Engineering, 8(10), 5-8. https://core.ac.uk/download/pdf/78487287.pdf

Tamilmani, K., Rana, N. P., \& Dwivedi, Y. K. (2019). Use of 'habit' is not a habit in understanding individual technology adoption: A review of UTAUT2 based empirical studies. In A. Elbanna, Y. K. Dwived, D. Bunker, \& D. Wastell (Eds.), Smart working, living and organising. TDIT 2018. IFIP advances in information and communication technology (Vol. 533, pp. 277-294). Springer. https://doi.org/10.1007/978-3-030-04315-5 19

Tan, P. J. B. (2013). Applying the UTAUT to understand factors affecting the use of English e-learning websites in Taiwan. SAGE Open, 3(4). https://doi.org/10.1177/2158244013503837 
Venkatesh, V., Brown, S. A., Maruping, L. M., \& Bala, H. (2008). Predicting different conceptualizations of system USE: The competing roles of behavioral intention, facilitating conditions, and behavioral expectation. MIS Quarterly: Management Information Systems, 32(3), 483-502. https://doi.org/10.2307/25148853

Venkatesh, V., Morris, M. G., Davis, G. B., \& Davis, F. D. (2003). User acceptance of information technology: Toward a unified view. MIS Quarterly: Management Information Systems, 27(3), 425478. https://doi.org/10.2307/30036540

Venkatesh, V., Thong, J. Y. L., \& Xu, X. (2012). Consumer acceptance and use of information technology: Extending the unified theory. MIS Quarterly, 36(1), 157-178. https://doi.org/10.1017/CBO9781107415324.004

Venkatesh, V., Thong, J. Y. L., \& Xu, X. (2016). Unified theory of acceptance and use of technology: A synthesis and the road ahead. Journal of the Association for Information Systems, 17(5), 328-376. https://doi.org/10.17705/1jais.00428

Zainol, Z., Yahaya, N., Yahaya, N. A. M., \& Zain, N. N. B. M. (2017). Factors influencing mobile learning among higher education students in Malaysia. International Journal of Advanced Scientific Research and Management, 2(8), 86-91. http://ijasrm.com/wpcontent/uploads/2017/08/IJASRM_V2S8 318_86_91.pdf

Zwain, A. A. A. (2019). Technological innovativeness and information quality as neoteric predictors of users' acceptance of learning management system: An expansion of UTAUT2. Interactive Technology and Smart Education, 16(3), 239-254. https://doi.org/10.1108/ITSE-09-2018-0065

Corresponding author: Jeya Amantha Kumar, jeya.amantha@gmail.com

Copyright: Articles published in the Australasian Journal of Educational Technology (AJET) are available under Creative Commons Attribution Non-Commercial No Derivatives Licence (CC BY-NC-ND 4.0). Authors retain copyright in their work and grant AJET right of first publication under CC BY-NC-ND 4.0.

Please cite as: Bervell, B., Kumar, J. A., Arkorful, V., Agyapong, E. M., \& Osman, S. (2022). Remodelling the role of facilitating conditions for Google Classroom acceptance: A revision of UTAUT2. Australasian Journal of Educational Technology, 38(1), 115-135.

https://doi.org/10.14742/ajet.7178 